Check for updates

The BMJ

Cite this as: BMJ 2020;370:m3708 http://dx.doi.org/10.1136/bmj.m3708 Published: 23 September 2020

\section{Covid-19: Government must publish results of pilots of contact tracing app, experts say}

Gareth lacobucci

Health experts have urged the government to publish the results of pilots of its covid-19 contact tracing app to demonstrate that it is effective and won't exacerbate health inequalities.

The app is being launched on 24 September in England and Wales to help reduce the spread of covid-19. But the government has not yet released the results of pilots that took place in August on the Isle of Wight and Newham in east London.

The charity the Health Foundation said that greater transparency was needed to show that the app was effective and ready for mass rollout. This will be crucial to building public confidence and encouraging people to download and use it, it argued.

As well as publishing data to confirm the app's overall effectiveness, ministers must demonstrate that the technology won't exacerbate existing health inequalities by leaving some people at greater risk of covid-19 than others, the foundation said. It said that piloting the app in Newham, one of England's most ethnically diverse and deprived boroughs, provided an opportunity to understand how it worked among different groups but said the findings should be made public to understand the app's effect.

The foundation also pointed to previously unreleased polling by Ipsos MORI on behalf of the charity that reinforced concerns of a potential "digital divide" along the lines of ethnicity, occupation, educational level, and age. The polling, conducted between 17 and 29 July among British adults, found that respondents from an ethnic minority background, women, the youngest and oldest age groups, routine and skilled manual workers, and unemployed people had a lower awareness of the government's plan to use a smartphone contact tracing app.

Josh Keith, senior fellow at the Health Foundation, said, "With a virus that is transmitted as quickly as covid-19, the automated contact tracing that the app promises could prove invaluable in reducing its spread.

"However, for any major nationwide public health intervention it is important the government publishes evidence that it is effective and ready for mass rollout in advance of its launch. Any data on the pilots that took place in August have been notably absent, leaving major questions over the app's effectiveness unanswered."

A spokesperson for the Department of Health and Social Care for England said that trials had shown the app to be accurate and responsive.

The spokesperson added, "We have spoken with groups with protected characteristics, such as age, ethnicity, and disability, those experiencing health inequalities, and those groups particularly impacted by coronavirus, and the app and supporting material will be available in multiple languages.” 